\title{
Preventative Disease Management and Grower Decision Making: A Case Study of California Wine-Grape Growers
}

\author{
Vicken Hillis, Mark Lubell, Jonathan Kaplan, and Kendra Baumgartner
}

First and second authors: Department of Environmental Science \& Policy, University of California, One Shields Avenue, Davis 95616; third author: Department of Economics, California State University Sacramento, 6000 J Street, Sacramento 95819; and fourth author: United States Department of Agriculture-Agricultural Research Service, Davis, CA 95616.

Accepted for publication 2 February 2017.

\begin{abstract}
Preventative disease management is challenging to farmers because it requires paying immediate costs in the hopes of returning uncertain future benefits. Understanding farmer decision making about prevention has the potential to reduce disease incidence and minimize the need for more costly postinfection practices. For example, the grapevine trunk-disease complex (esca, Botryosphaeria dieback, Eutypa dieback, and Phomopsis dieback) significantly affects vineyard productivity and longevity. Given the chronic nature of the infections and inability to eradicate the fungal pathogens, the preventative practices of delayed pruning, applications of pruning-wound protectants, and double pruning (also known as prepruning)

are the most effective means of management. We surveyed wine-grape growers in six regions of California on their use of these three practices. In spite of acknowledging the yield impacts of trunk diseases, a substantial number of respondents either choose not to use preventative practices or incorrectly adopted them in mature vineyards, too late in the disease cycle to be effective. Growers with more negative perceptions of cost efficacy were less likely to adopt preventative practices or were more likely to time adoption incorrectly in mature vineyards. In general, preventative management may require strong intervention in the form of policy or extension to motivate behavioral change.
\end{abstract}

Grapevine trunk diseases are widespread in the United States (Urbez-Torres et al. 2006) and around the world (Bertsch et al. 2013). This complex of diseases, which includes esca, Botryosphaeria dieback, Eutypa dieback, and Phomopsis dieback (Fig. 1), causes substantial losses to growth and yields as a vineyard ages (Munkvold et al. 1994), with important economic impacts at both the farm and industry levels (Siebert 2001; Sipiora and Cuellar 2014). Adoption of preventative practices starting in young, healthy vineyards is critical to achieving adequate yields and, thus, positive returns, in the long term (Kaplan et al. 2016). Because the ultimate outcome of inadequate prevention is the very costly practice of premature replanting (Sipiora and Cuellar 2014), trunk diseases contribute indirectly to the environmental costs associated with vineyard establishment, including increased expenditures of fossil fuel (Smyth and Russell 2009) and vineyard expansion into natural habitats (Merenlender 2000). Effective prevention of trunk diseases thus benefits both the economic and environmental health of the wine-grape industry.

We surveyed pest-control advisers (PCAs) in California who make recommendations to grape growers and found that they recommend preventative practices at higher rates in vineyards with increasing levels of disease incidence, rather than timing preventative practices correctly by using them in vineyards with few to no symptomatic vines (Hillis et al. 2016). This finding was surprising; we expected

Corresponding author: K. Baumgartner;

E-mail address: Kendra.Baumgartner@ars.usda.gov

Mention of trade names or commercial products is solely for the purpose of providing specific information and does not imply recommendation or endorsement by the U.S. Department of Agriculture. USDA is an equal opportunity provider and employer.

*The $\boldsymbol{e}$-Xtra logo stands for "electronic extra" and indicates that one supplementary file is published online.

This article is in the public domain and not copyrightable. It may be freely reprinted with customary crediting of the source. The American Phytopathological Society, 2017.
PCAs to recognize the importance of adopting preventative practices before symptoms appear. Do growers have the same habits? In contrast to PCAs, growers must bear the long-term cost of foregoing prevention, which might facilitate their use of preventative practices in young, uninfected vineyards. Recognizing the relative advantage of prevention, however, is difficult because the benefits of prevention are uncertain and accrue in the long term. Learning about these benefits is constrained by the difficulty of conducting on-farm trials of preventative practices in a perennial cropping system, and the time lag of one or more years between infection and symptom expression of trunk diseases (Czemmel et al. 2015). Indeed, symptomatic vines do not become noticeable until the vineyard is mature; around year 10, approximately $20 \%$ of vines will show symptoms (Duthie et al. 1991) and, up to this point, yield losses are relatively minor (Munkvold et al. 1994).

Practices are adopted when growers perceive them to have a clear advantage over other options (Rogers 2003). Preventative practices typically involve paying immediate costs in the hope of possibly accruing benefits later. The fact that the benefits of prevention are delayed, and therefore inherently uncertain, may serve to obscure their relative advantage to growers. To accurately assess the relative advantage of a preventative practice, a grower must take a long-term perspective, which can be both psychologically and financially challenging. In the context of trunk diseases, adoption of preventative practices requires paying immediate costs but the benefits (i.e., lack of yield losses) are not apparent until 4 to 8 years later (Kaplan et al. 2016). Nonetheless, the common alternative to prevention, which is to manage trunk diseases after infection through the postinfection practice of vine surgery (Sosnowski et al. 2011), is a more costly approach than any of the preventative practices (Hillis et al. 2016).

One way that growers construct their perceptions of relative advantage is by conducting small-scale, on-farm trials. This type of experiential learning has been shown to be an important determinant of overall adoption levels (Abadi Ghadim and Pannell 1999; Warner 1974). The perennial nature of wine grape plants makes it difficult for growers to conduct such trials, because it takes several years before the outcomes of a trial become apparent. Indeed, few researchers have taken the time to evaluate the actual 
effect of preventative practices in terms of improvements in yield (one exception is the study by Gu et al. [2005]). Furthermore, the long time frame increases the number of potentially confounding factors that might arise over the course of a trial, obscuring the effects on yields of the preventative practices themselves. The difficulty of conducting on-farm trials of preventative practices thus serves as a barrier to the development of positive perceptions about the practices via experiential learning which, in turn, can hinder adoption. For example, adoption of management practices intended to prevent dryland salinity in western Australia was hindered in large part by the fact that the salinization process, which is obscured underground and can vary from site to site depending on soil type, takes several years to have noticeable effects on crop growth and yield (Pannell et al. 2006).

Without the ability to conduct convenient on-farm trials as a form of experiential learning, growers inevitably rely on social information to shape their perceptions (Hoffman et al. 2015). Social information comes in various forms, including informal advice from friends or observations of neighbors, and formal learning from textbooks or instructional classes. Regardless of the source, individual perceptions of relative advantage shaped by social information are critical to whether or not a grower makes a decision to adopt. The long latent period between infection and symptom expression in trunk diseases, however, may lead to misperceptions about practice efficacy spreading among growers. Because the wood infections caused by trunk diseases are internal and there is no method for detection before symptoms appear, growers may be adopting preventative practices after infection without actually knowing it. Subsequently, upon symptom expression, a grower might conclude that the preventative practice was ineffective.
In a system where social information is of particular importance, these faulty negative perceptions may easily spread among practitioners and further inhibit adoption.

We examine the adoption of three preventative practices for grapevine trunk diseases. A survey of wine-grape growers in California was conducted in person at six education and outreach workshops, to examine grower perceptions of and decisions about preventative trunkdisease management. Our objectives were to (i) assess whether growers routinely use preventative practices; (ii) determine whether growers time their adoption of preventative practices correctly, by employing them before infection occurs; and (iii) examine differences in usage and timing as a function of the different preventative practices, geographic region, and grower perceptions of cost efficacy. Understanding why managers choose to adopt a particular strategy is critical to the effective management of crop diseases (Gent et al. 2013). We also highlight the outreach implications of our findings.

\section{MATERIALS AND METHODS}

Survey design. Because of the complexity of wine-grape production, many different individuals potentially influence decision making in trunk disease management. In order to understand who these important individuals are, we conducted 22 semistructured interviews with key industry stakeholders and had other discussions with our research advisory board, consisting of University of California Cooperative Extension (UCCE) farm advisors and other industry representatives. As a result of this qualitative research, we designed our survey to target the full range of key decision makers in

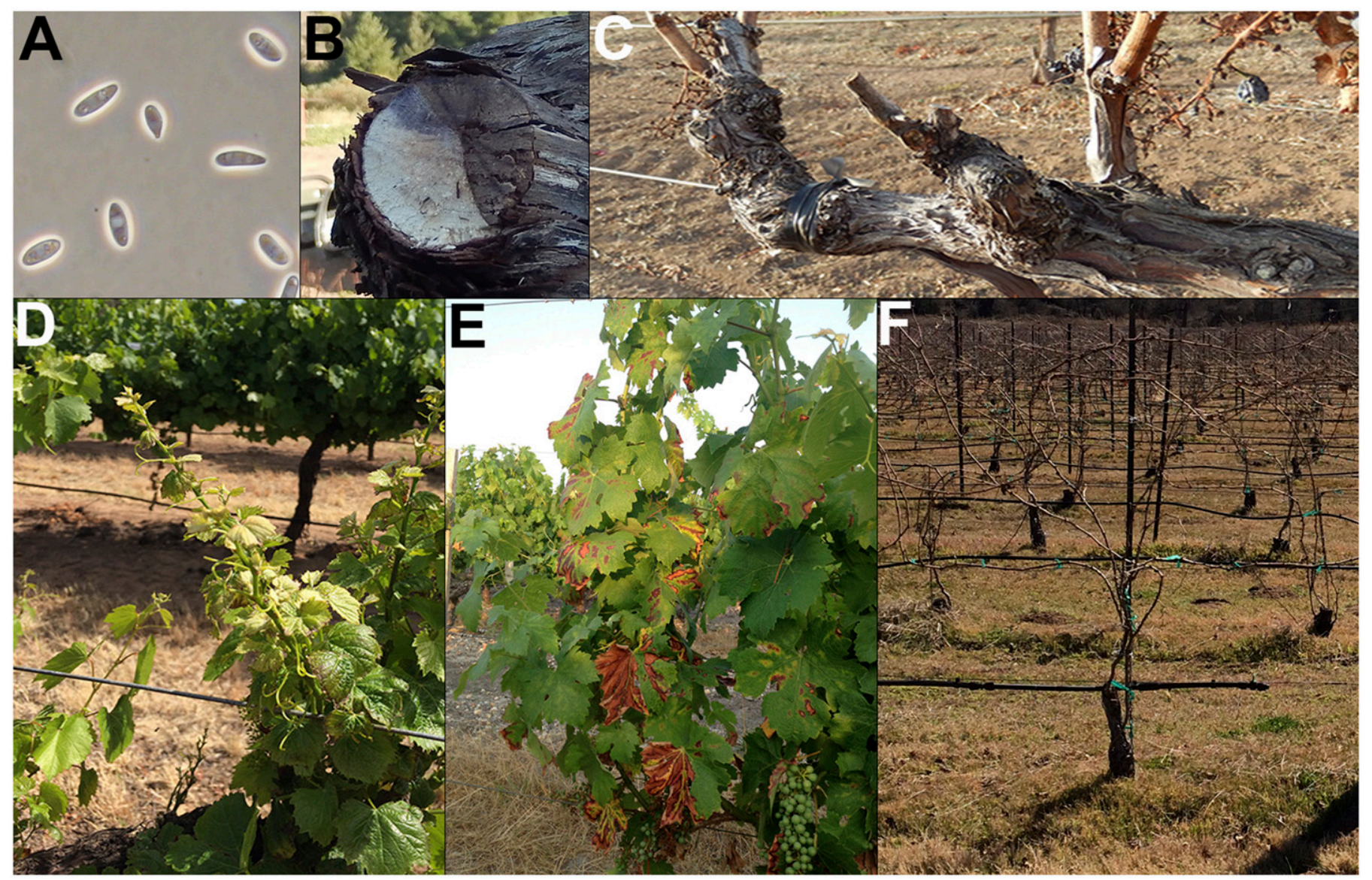

Fig. 1. Grapevines are infected by trunk diseases $\mathbf{A}$, when the microscopic spores of the fungal pathogens land and germinate on pruning wounds, a process that occurs during the rainy season, when the dormant vines are pruned as part the standard viticultural practices and when the spores are produced with rain. B, A wood canker develops internally, near the point of infection. After several months to several years, depending on the aggressiveness of the pathogen and the susceptibility of the vine, the fruiting position (spur) $\mathbf{C}$, adjacent to the wood canker dies and, thus, the grape clusters which would have formed on the shoots are lost. Foliar symptoms of trunk diseases D, Eutypa dieback and E, esca take months to years to appear. The only way to eradicate a trunk disease infection is to cut out cankered wood and $\mathbf{F}$, retrain the vine, a practice known as "vine surgery". 
vineyards, including growers, managers, owners, consultants, and winemakers. In order to ensure that our sample of respondents only included individuals who play a direct role in disease management, we asked respondents if they make, or advise others who make, trunkdisease management decisions. We report and analyze responses for those individuals who responded "yes" to this question. For convenience, we refer to all respondents as "growers". We asked questions about the growers (job type, years of experience, and California crush districts where growers work) and the incidence of trunk diseases in their vineyards. The main body of the survey focused on a set of three preventative practices (Table 1). Each practice was defined in the survey, and growers were asked the same set of questions for each practice: frequency of usage, when they adopt each practice in terms of vineyard age, and their perceptions of the costs and benefits of each practice. Our sample includes broad coverage of wine-grape growers with respect to specific job category, geographic region, number and vineyard size of clients advised, years of experience in the industry, and percentage of time spent in the vineyard (Table 2). The response rate, albeit for the growers who attended the meeting in the first place, was high, ranging from just under $70 \%$ to above $90 \%$ across the sessions.

Survey distribution. The survey was conducted using the Turning Point electronic audience response system (Turning Technologies, Youngstown, $\mathrm{OH}$ ) at meetings organized by local UCCE viticulture farm advisors or regional grower groups between November 2013 and February 2014. Growers answered each question as it was displayed to the audience, using a remote device to key in the answer. We report the number of responses collected in each region, and other characteristics of our grower sample were tallied and summarized.

Statistical analyses. We used a Bayesian modeling framework to construct and fit statistical models to our data. Outcome variables included the frequency of practice usage (scale of 1 to 5, ranging from "Never" to "Always"), timing of practice usage (scale of 1 to 4, ranging from "First 3 years" to "Year 12 or later"), and cost-efficacy ratings (scale of 1 to 5, ranging from "Very ineffective" to "Very effective"). These outcomes are all ordinal measures; therefore, we modeled Bayesian ordered logistic, or proportional odds, regressions for each outcome (McCullagh 1980). These models estimate parameter values for predictor variables in the model as well as a vector of cut points, which represent the probability that an outcome is in a given category or any of the categories below it. The cumulative log-odds of a given outcome category $(m)$ is thus given as:

TABLE 1. Preventative practices for trunk diseases in California vineyards, as defined in our survey of wine-grape growers

\begin{tabular}{|c|c|}
\hline Practice & Definition \\
\hline Delayed pruning & $\begin{array}{l}\text { Prune late in the dormant season (February or later) by } \\
\text { hand. }\end{array}$ \\
\hline Double pruning & $\begin{array}{l}\text { Prune early in the dormant season (December or } \\
\text { January) with a mechanical-pruning machine; partially } \\
\text { prune canes to a length of approximately } 0.2 \mathrm{~m} \text {. Prune } \\
\text { again late in the dormant season (February or later) by } \\
\text { hand; completely prune canes down to two-bud spurs. }\end{array}$ \\
\hline Protectant & $\begin{array}{l}\text { After pruning, apply protectant by hand (with a } \\
\text { paintbrush or sponge to cover pruning wounds) or as a } \\
\text { spray application (with tractor or ATV-mounted spray } \\
\text { nozzles). Protectants registered in California for } \\
\text { dormant-season application: } \\
\text { 1. Boric acid (Tech-Gro B-Lock; Nutrient Technologies, } \\
\text { Inc., Dinuba, CA) for hand application } \\
\text { 2. Myclobutanil (Rally; Dow Agrosciences LLC, } \\
\text { Indianapolis, IN) for hand and spray applications } \\
\text { 3. Thiophanate-methyl (Topsin M WSB; United } \\
\text { Phosphorus, Inc., King of Prussia, PA) for hand and } \\
\text { spray applications } \\
\text { 4. VitiSeal (VitiSeal International LLC, San Diego, CA) } \\
\text { for hand application. }\end{array}$ \\
\hline
\end{tabular}

$$
\log \frac{\operatorname{Pr}(y \leq m \mid \mathbf{x})}{\operatorname{Pr}(y>m \mid \mathbf{x})}=\alpha_{m}-\mathbf{x} \boldsymbol{\beta}(1 \leq m \leq \mathrm{M})
$$

where $m$ is an outcome category, $\mathrm{x}$ is a vector of outcome variables, $\alpha$ is a cut point, and $\beta$ is a vector of logit coefficients (Fullerton 2009). For these models, we fit at least four candidate models in each case: a null model with no predictors, one model with two dummy variables for each practice, one model with five dummy variables for each geographic region, and one model with all regional and practice dummy variables as the predictor variables. For the model examining the influence of cost-efficacy perceptions on usage and timing of adoption, we added cost-efficacy perceptions to the region and practice dummy variables as a final predictor variable.

All models were fitted using fixed effects for the predictor variables, with the unit of analysis being the grower-practice combination. For all parameters and models, we specified weakly regularizing Gaussian priors, with a mean of 0 and a standard deviation of 100 . For each variable, we report the values of the corresponding $\beta$ coefficients, which are the mean values of the posterior distributions and represent the change in the cumulative log-odds of moving to a higher outcome category as a function of a unit change in the corresponding predictor variable. We also report the corresponding 0.95 posterior credibility intervals (CI), which represent the central $95 \%$ of the posterior distribution. This approach is an alternative to null hypothesis significance testing, which assesses whether or not a coefficient is significantly different from zero (or that responses between groups are significantly different) at some normative level. It allows us to calculate the quantity of interest, the posterior probability of our hypotheses, given the data observed and any prior information we have.

In order to better understand and visualize the results of model fitting beyond just reporting posterior estimates, we generated and plotted predictions from the model with all predictor variables. These predictions represent the probability of the outcome variable being in a particular category as a function of the values of the predictor variables. For visual clarity and ease of understanding, in the main text we provide plots that display only the mean predictions. For

TABLE 2. Demographic and other characteristics of grower survey respondents ${ }^{\mathrm{a}}$

\begin{tabular}{lcc}
\hline Survey item & Responses & $\begin{array}{c}\text { Percentage } \\
\text { of total }(\%)^{\mathrm{b}}\end{array}$ \\
\hline Job category & & \\
$\quad$ Grower, vineyard manager & 242 & 70 \\
Consultant, pest-control adviser & 85 & 25 \\
Owner & 115 & 33 \\
Winemaker, winery associate & 45 & 13 \\
Other & 44 & 13 \\
Region (Crush districts) & & \\
Central coast $(7,8)$ & 72 & 20 \\
Mendocino and Lake Counties $(1,2)$ & 47 & 14 \\
Napa (4) & 82 & 24 \\
Northern San Joaquin Valley $(11)$ & 67 & 19 \\
Sierra foothills $(10)$ & 35 & 10 \\
Sonoma (3) & 42 & 12 \\
Experience & & \\
1-10 years & 127 & 37 \\
11-20 years & 108 & 33 \\
21-30 years & 46 & 14 \\
$31-40$ years & 39 & 12 \\
$>40$ years & 15 & 3 \\
Hectares of production & & \\
$<40$ & 143 & 44 \\
$41-200$ & 63 & 19 \\
201-400 & 39 & 12 \\
$>400$ & 77 & 24 \\
\hline
\end{tabular}

a California wine-grape crush districts in which surveys were conducted (geographic locations and descriptions of crush districts available at https:// www.nass.usda.gov/Statistics_by_State/California/Publications/Grape_Crush/ Grape\%20Crush\%20Districts\%20Map.pdf).

b Percentages for job category sum to greater than $100 \%$ because respondents could select more than one category. 
completeness, we reproduce all plots, incorporating visualization of the variation around the mean predictions in Supplementary File S1. All analyses were conducted in $\mathrm{R}$ version 3.2.1, using the base, lme4, rethinking, and ggplot2 packages (R Core Team 2013).

\section{RESULTS}

Variation in usage of practices among regions and practices. Growers in all six regions acknowledged the presence of trunk diseases in their vineyards and negative effects on yields. Mean grower-estimated disease incidence was relatively consistent among regions, as follows: 8\% (Foothills), 13\% (Sonoma, Central Coast, Napa, and Foothills), and $18 \%$ (Lodi). Also relatively consistent among regions were reports of the yield decline due to trunk diseases, as follows: 9\% (Foothills), 10\% (Central Coast and Mendocino), 11\% (Sonoma and Napa), and 14\% (Lodi).

There was substantial variation in adoption among the three practices within each region (Fig. 2), although the consistent pattern across regions was delayed pruning as the most commonly adopted $\left(\beta_{\text {Delayed }}=0.91, \mathrm{CI}: 0.67,1.15\right)$, double pruning as the least commonly adopted $\left(\beta_{\text {Double }}=-0.057\right.$, CI: $\left.-0.80,-0.33\right)$, and pruning-wound protectants as intermediate ( $\beta$ values are relative to $\beta_{\text {Protectant }}$ ). There was variation in adoption across regions (Fig. 2), with Napa having the highest level of adoption $\left(\beta_{\mathrm{Napa}}=0.59, \mathrm{CI}\right.$ : $0.30,0.87)$, Mendocino having the lowest $\left(\beta_{\text {Mendocino }}=-0.09, \mathrm{CI}\right.$ : $-0.42,0.24)$, and the Central Coast as intermediate $(\beta$ values are relative to $\left.\beta_{\text {Central Coast }}\right)$. For example, this best-fitting model predicts that over half of growers in Napa will always use delayed

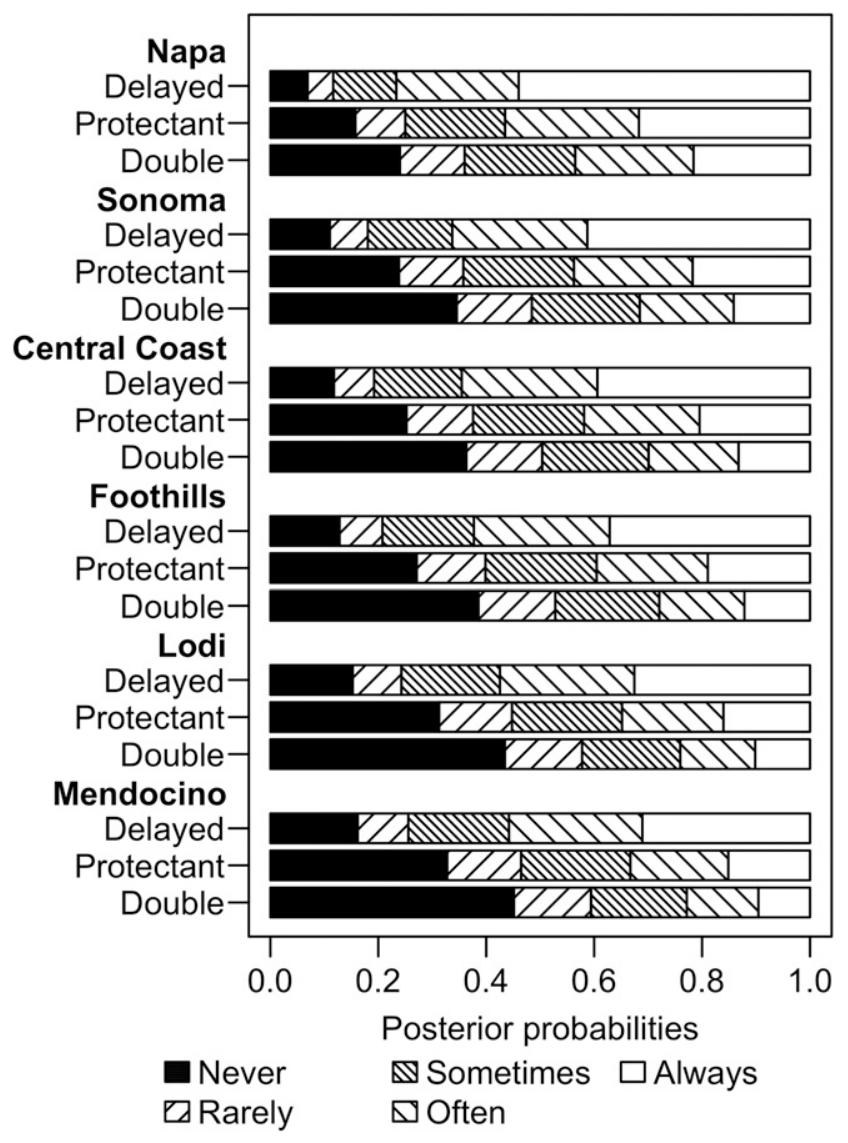

Fig. 2. Posterior probability of a grower selecting a given response for frequency of use (Never, Rarely, Sometimes, Often, or Always) for each combination of the six geographic regions and three practices. At meetings (one per region) in six grapegrowing regions of California, wine-grape growers were asked how often they use delayed pruning (Delayed), double pruning (Double), and pruning-wound protectants (Protectant) pruning (the most common practice in all regions), compared with only $30 \%$ in Mendocino (Fig. 2).

Variation in timing of practices among regions and practices. We find less variation among both practices and regions in timing of adoption than we do with adoption overall (Fig. 3). The practice adopted the earliest, however, is not delayed pruning, but pruning-wound protectants $\left(\beta_{\text {Protectant }}=-0.22, \mathrm{CI}:-0.54,0.10\right.$; note that the outcome variable here is year of adoption; thus, a negative $\beta$ coefficient implies earlier adoption; $\beta$ values are relative to $\left.\beta_{\text {Delayed }}\right)$. Double pruning is adopted the latest $\left(\beta_{\text {Double }}=0.24, \mathrm{CI}\right.$ : $-0.07,0.56)$. In all six regions, over $50 \%$ of growers did not adopt double pruning until vineyards were $\geq 8$ years old (Fig. 3 ), which is typically considered when vineyards are mature and trunk diseases are present (Duthie et al. 1991). We find relatively little variation among regions in timing of adoption, with Napa adopting the earliest $\left(\beta_{\text {Napa }}=-0.13, \mathrm{CI}:-0.49,0.22\right)$, Mendocino adopting the latest $\left(\beta_{\text {Mendocino }}=0.66, \mathrm{CI}: 0.29,1.12\right)$, and the Central Coast as intermediate $\left(\beta\right.$ values are relative to $\beta_{\text {Central Coast). In Napa, }}$ Sonoma, Central Coast, and Lodi regions, over half of growers adopt pruning-wound protectants (the earliest practice adopted) in the first 3 years or in years 4 to 7 (Fig. 3), which represents vineyard ages typically characterized by few to no symptomatic vines (Duthie et al. 1991). In the Foothills and Mendocino, all three practices were adopted by the majority of growers in vineyards $\geq 8$ years old (Fig. 3).

Variation in perceptions of cost efficacy of practices among regions and across practices. In contrast to usage and timing of practices, there was substantial variation in perceptions of cost efficacy across both regions and practices. Delayed pruning received the most positive ratings $\left(\beta_{\text {Delayed }}=0.64, \mathrm{CI}\right.$ : 0.34, 0.93),

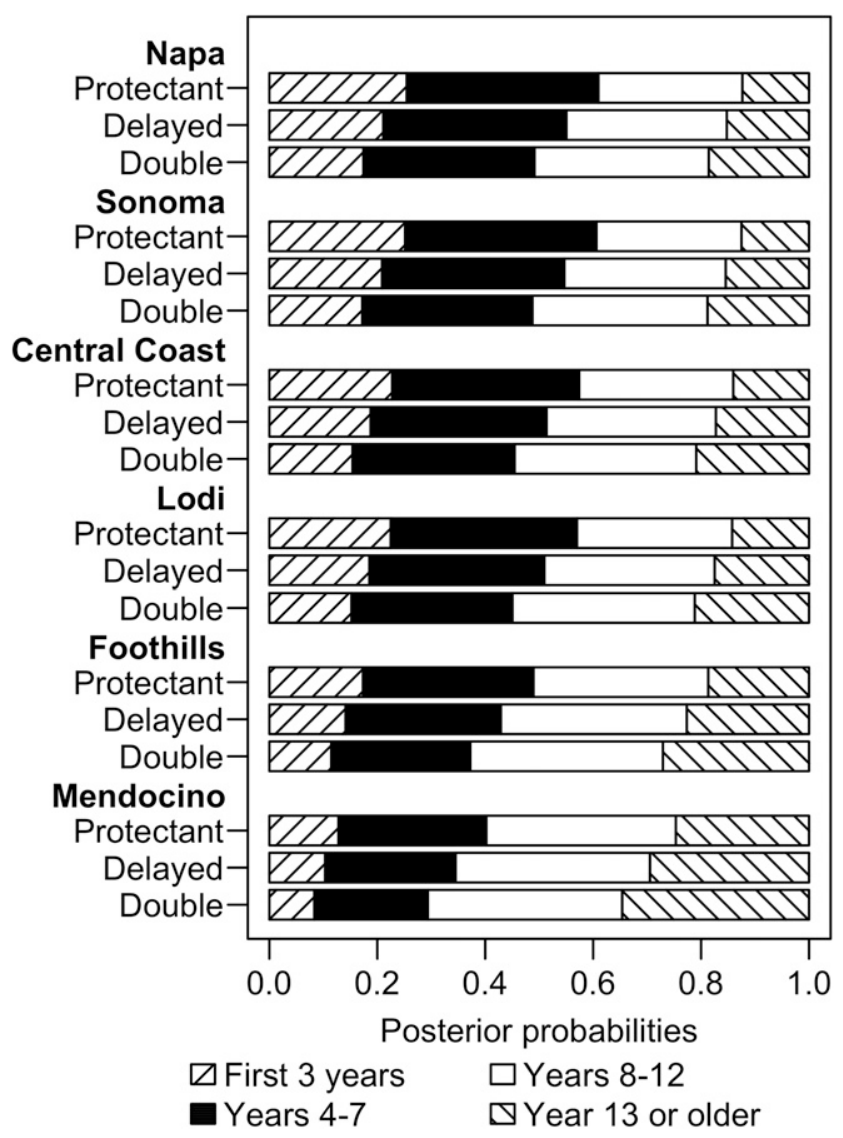

Fig. 3. Posterior probability of a grower selecting a given response for timing of usage (vineyard age ranges of the first 3 years, years 4 to 7 , years 8 to 12 , and year 13 or older) for each combination of the six geographic regions and three practices. Growers were asked the vineyard age when delayed pruning (Delayed), double pruning (Double), and pruning-wound protectants (Protectant) were adopted. 
double pruning received the least positive $\left(\beta_{\text {Double }}=-0.43, \mathrm{CI}\right.$ : $-0.73,-0.13)$, and delayed pruning was intermediate ( $\beta$ values are relative to $\left.\beta_{\text {Delayed }}\right)$. The regions grouped loosely into four regions with positive cost-efficacy estimates (Napa, Sonoma, Central Coast, and Mendocino) and two regions with relatively negative perceptions of cost efficacy: Foothills $\left(\beta_{\text {Foothills }}=-1.28, \mathrm{CI}:-1.86\right.$, $-0.70)$ and Lodi $\left(\beta_{\text {Lodi }}=-1.64\right.$, CI: $\left.-2.19,-1.10\right)$ (Fig. 4). In the Foothills and Lodi, fewer than $50 \%$ of growers perceived any practice as somewhat to very effective (Fig. 4).

Usage and timing as a function of perceptions of cost efficacy. There was a strong effect of perceived cost efficacy on the probability of adoption $(\beta=0.48$, CI: $0.36,0.60)$ such that, as the cost-efficacy rating improves, the probability of adoption increases (Fig. 5A). The cumulative probability of each response category on the $y$-axis for different levels of perceived efficacy on the $x$-axis is shown in Figure 5. For example, a practice perceived as very ineffective was never used by over $20 \%$ of growers, whereas it was never or rarely used by over $40 \%$ of growers, and never, rarely, or sometimes used by approximately $70 \%$ of growers. Practices perceived as very effective were used always by $43 \%$ of growers (averaged across regions and practices), whereas practices perceived as very ineffective were used rarely or never by $47 \%$ of growers (Fig. 5A). There was a substantial effect of cost-efficacy ratings on the timing of adoption $(\beta=-0.24$, CI: $-0.38,-0.11)$ such that, as cost-efficacy ratings increase, the probability of adoption in vineyards $\geq 8$ years old (i.e., mature, diseased vineyards) decreases (Fig. 5B). In other words, proper timing of adoption in vineyards up

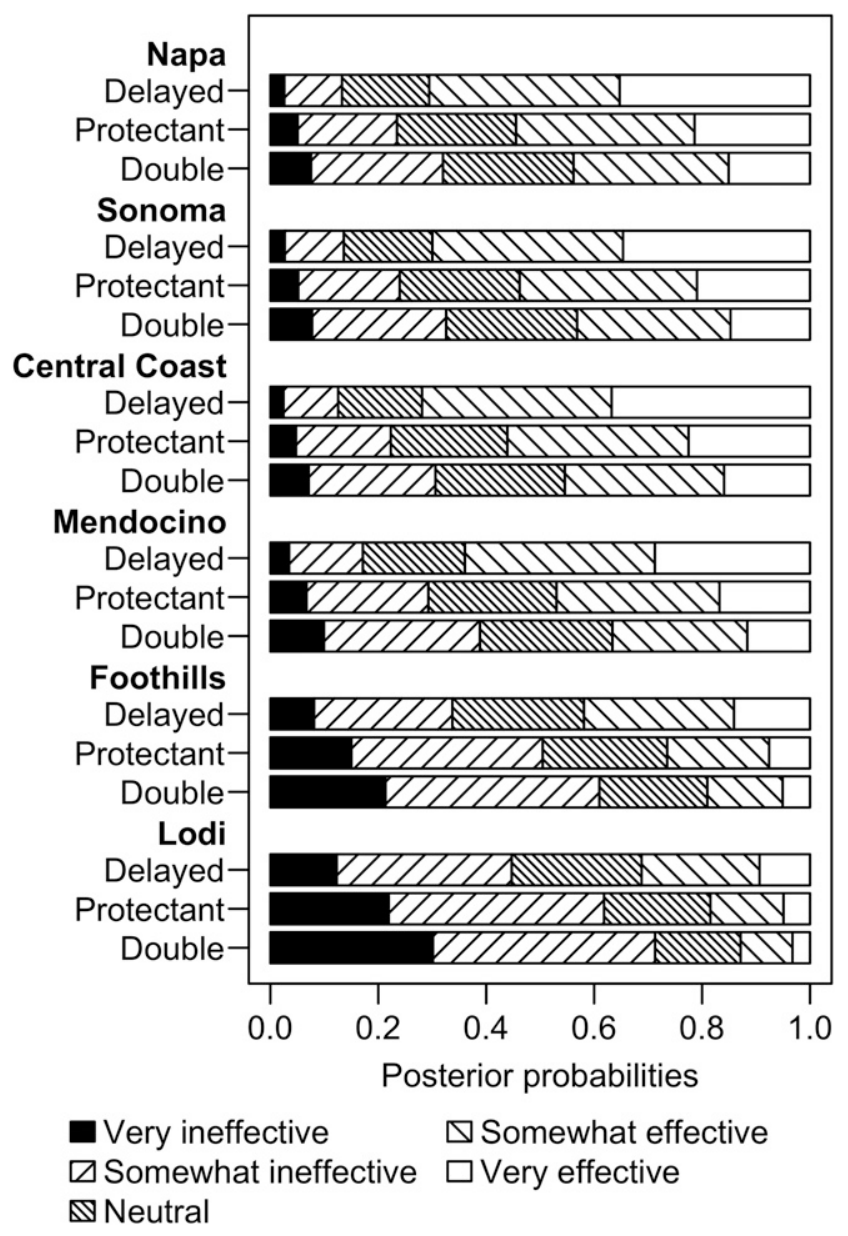

Fig. 4. Posterior probability of a grower selecting a given cost-efficacy rating (Very ineffective, Somewhat ineffective, Neutral, Somewhat effective, or Very effective) for each combination of the six geographic regions and three practices. Growers were asked the cost efficacy of delayed pruning (Delayed), double pruning (Double), and pruning-wound protectants (Protectant). to 3 years old increases as cost-efficacy ratings are more positive (Fig. 5B).

\section{DISCUSSION}

Every vineyard in California eventually becomes infected by one or a combination of trunk diseases (Gubler et al. 2013). The growers we surveyed acknowledged the impact of trunk diseases on yields and our survey results indicate that some growers use preventative practices. However, in spite of evidence that the practices are effective before infection (Petzoldt et al. 1981; Rolshausen et al. 2010; Weber et al. 2007), many growers adopt preventative practices late in the vineyard lifespan, after trunk diseases are already present in the vineyard. Only roughly 30 to $60 \%$ of adopters first adopt in relatively young vineyards (7 years old or younger), and even fewer (10 to $25 \%$ ) adopt in very young vineyards ( $<4$ years old), which we assume is when preventative practices are likely to be most effective. More growers in certain regions (Foothills and Mendocino) have worse timing than in other regions (Napa and Sonoma).

Aside from the fact that trunk diseases do not become apparent until the vineyard is mature, our findings of incorrect adoption in mature vineyards may be due, in part, to the barriers inherent to preventative management and the constraints on experiential and social learning in this system. Our findings may also be due to the fact that most published field trials on preventative practices (Petzoldt et al. 1981; Rolshausen et al. 2010; Weber et al. 2007) are of limited duration (only 1 or 2 years of data). When presented to growers through extension materials, such results are difficult to apply to a long-lived host that is planted with the intention of producing a high-value crop for decades. Furthermore, the type of data presented in such studies consists primarily of pathogen recovery rates (i.e., the percentage of inoculated pruning wounds not protected by a practice). Such measurements of efficacy have epidemiological significance for researchers, who make the assumption that the more pruning wounds protected by a practice, the fewer yields lost in the long run. In this sense, regionally situated, long-term research directly measuring disease incidence in field settings as a function of preventative disease management would provide an important validation of existing research as well as produce findings that are potentially more convincing to growers. Differences in how experts and practitioners evaluate disease risk (McRoberts et al. 2011) or the risk of weed infestations (Jabbour et al. 2013) can lead to a disconnect between research on agricultural practices and, in turn, adoption by practitioners.

Although we uncovered generally late adoption for all practices and regions, there is substantial variation in both usage and timing among practices and regions. The most common practice in all regions was delayed pruning, which is also the least expensive practice (Hillis et al. 2016). It is worth noting, however, that even a preventative practice which is relatively inexpensive, such as delayed pruning, can have indirect costs if it is incompatible with other aspects of the farming system. For example, delayed pruning can delay grapevine growth in spring which, in turn, can delay fruit ripening later in the growing season (Keller 2015). In contrast, the least common practice was double pruning, which is the most expensive and costs approximately $\$ 100$ more per hectare than delayed pruning (Hillis et al. 2016).

For all practices, Napa and Sonoma had the highest rates of adoption and the earliest timing in young vineyards. These regions also have the highest pricing per ton of fruit among those we examined (Kaplan et al. 2016). Because high practice cost was shown to be associated with lower recommendation rates by PCAs, at least for preventative practices (Hillis et al. 2016), it is possible that growers with higher net revenues are more likely to take on the annual costs of adopting preventative practices. At this broad regional scale, there are no obvious patterns of adoption associated with regional differences in rainfall, as we might expect given that the pathogens are rain dispersed (Úrbez-Torres et al. 2010). Indeed, 
growers reported consistent levels of disease incidence among regions. The risk of a vineyard becoming infected by trunk diseases is not higher in Napa and Sonoma, but the difference in net benefits between a healthy and a diseased vineyard is much higher in these two regions: $\$ 65,442$ and $\$ 32,970$ per hectare, respectively, over a 25 -year vineyard lifespan (Kaplan et al. 2016). These values are approximately 1.5 to 4 times higher than those of the other regions. Therefore, growers in lower-revenue regions may be employing a type of "safety-first" approach, in which their first priority is to survive the immediate term, rather than to maximize profits in the long term. Indeed, the net benefits per hectare from adoption of any of the preventative practices in a 'Cabernet Sauvignon' vineyard in Napa, for example, are approximately four times that of a vineyard in Lodi (Kaplan et al. 2016).

Across regions, the cost efficacies of the practices were ranked similarly according to actual practice costs, with more growers having positive perceptions of the least costly practice (delayed pruning), and fewer growers having positive perceptions of the most costly practice (double pruning). Importantly, we found a negative association between perceptions of cost efficacy and both adoption and timing of adoption. Given our understanding of the importance of relative advantage, it is not surprising that negative perceptions of cost efficacy corresponded to both low and later adoption rates. An important subsequent question, then, is how growers come to hold these negative perceptions in the first place. We posit that barriers to learning play an important role. Because wine grape plants are perennial, experiential learning about the management practices takes literally years to complete and, therefore, growers are constrained in their ability to assess for themselves the efficacy of the practices. Because of the multiyear latent period between infection and symptom expression, growers may be adopting preventative practices after infection occurs without realizing it, then developing negative misperceptions about poor practice efficacy as a result. These negative misperceptions then potentially spread via social learning among growers. Our survey did not collect the data required to directly examine whether these barriers to learning are leading to negative cost-efficacy perceptions. However, we argue that, when uncertainty about a practice's benefit is high, coupled with the fact that a grower's ability to reduce uncertainty through on-farm trials is limited, adoption is likely to be limited as well (Lubell et al. 2011). This highlights the need for extension to play a role in reducing uncertainty about preventative practices, specifically in ways that focus on (i) the long-term benefits of prevention and (ii) sitespecific figures. Our previous study of PCAs and their role in trunk disease prevention indicated that PCAs recommend postinfection control as commonly as they do prevention, and that these recommendations are associated with grower behavior (Hillis et al. 2016). Thus, to the extent that PCAs play an important role in maintaining the disconnect between research findings that support the use of prevention and grower behavior, they also present an opportunity for improving communication with growers. Here, again, the same research findings that might persuade growers more effectively-situated, long-term data demonstrating the effect of preventative disease management on disease incidence-is likely to also persuade PCAs to promote prevention among their grower clientele.

Our study documents a problem in California with respect to management of trunk diseases: incorrect timing of preventative practices. Similar challenges are likely to be found for other crops and regions when growers are faced with the challenge of having preventative disease-management practices as the most effective means of control. We identify some of the social and decision-making processes that are likely to drive these problems. To untangle the various dimensions likely to be important to grower decision making, risk preferences and perceptions of disease risk need to be evaluated. Because we sampled all growers who attended our outreach meetings, our sample is not random with respect to the overall population of growers. We think our findings are still important, however, for two main reasons. First, we have reasonable coverage of the population of growers with respect to a number of characteristics, as was described earlier (e.g., the sample includes comparable proportions of growers farming small, medium, and large vineyards). Second, we expect that, if anything, we have a sample of growers who are more likely than average to use preventative practices. Our respondents include those growers who attend outreach and education meetings. These are likely to be the growers who are most informed, participatory, and innovative. Among these growers, our core finding is that they neglect or misuse preventative practices. Thus, we suspect that these results would be even more stark if we had an actual random sample from the population.

Based on these findings, we can make a number of specific recommendations relevant to research, outreach, education, and extension. These include, among the obvious, to focus efforts on practices and regions with relatively low rates of adoption, and to
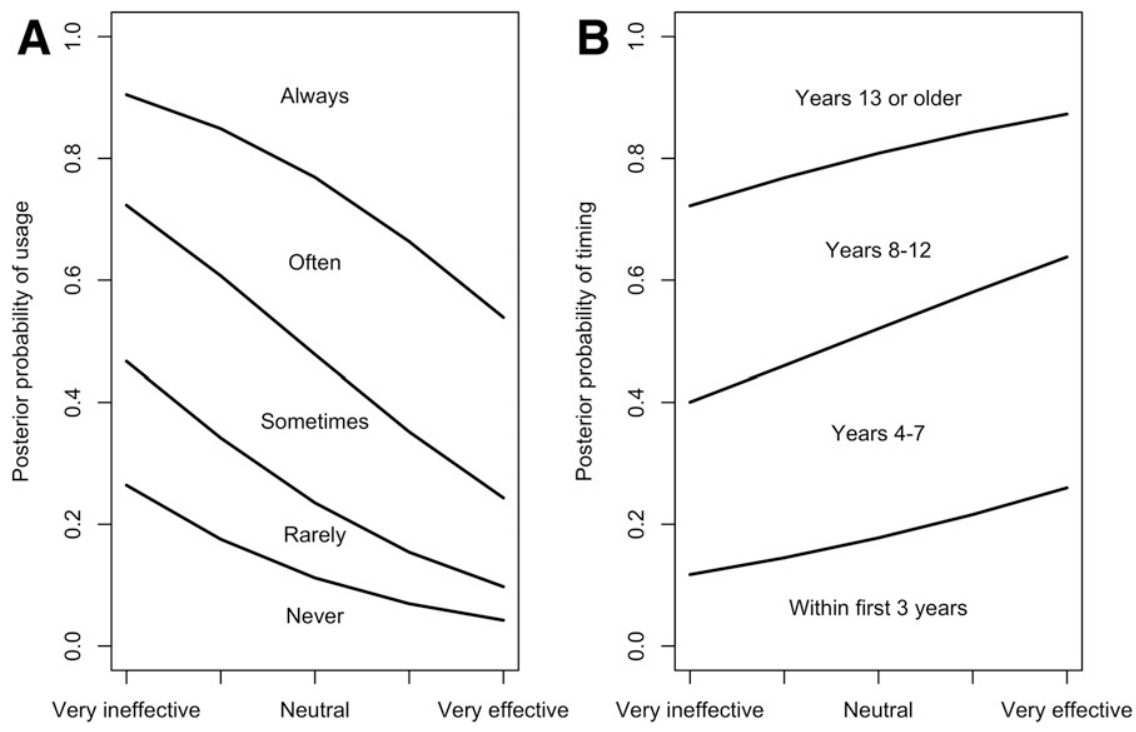

Fig. 5. Cumulative posterior probabilities for the five different levels of cost-efficacy ratings (very ineffective to very effective) of $\mathbf{A}$, a given usage category (Never, Rarely, Sometimes, Often, or Always) and B, a given timing category (within first 3 years, years 4 to 7 , years 8 to 12, or year 13 or older). Text labels within plotting region refer to areas bounded by the lines immediately above and below the label and not to the curves themselves. Thus, the area below a given curve represents the cumulative probability that a response falls into that category or one of the categories below it for a particular level of perceived efficacy. For example, a very effective practice was never used by fewer than $10 \%$ of growers, and was never, rarely, or sometimes used by over $20 \%$ of growers. 
highlight the long-term relative advantage of adopting preventative practices early in the lifespan of a vineyard, before infection sets in. Additionally, there is a need to highlight the high likelihood of infection in all vineyards among all California grape-growing regions. Because growers cannot easily conduct on-farm trials to test preventative practices, it is critical to produce information that helps convince growers that a particular practice is feasible in their individual vineyard. Regional field trials might be useful in this regard, and can function both as long-term experiments and as demonstration plots, thus serving the dual purpose of producing needed long-term data on the efficacy of preventative practices, as well as informing growers about regional relevance. Because social information is critical to grower decision making in systems where on-farm trials are difficult to conduct, extension efforts should be geared toward building information networks that function to spread effective information about the use of preventative practices. Network-smart extension practices such as prioritizing extension activities that facilitate building and strengthening informal social networks among growers themselves could be useful in this regard. Finally, conducting long-term, region-specific research in the field that directly examines the effect on yields of preventative disease management, while expensive and time-consuming, will be an important means of both validating existing research on the efficacy of prevention and producing findings that are more easily communicated and more convincing to growers. The challenge of convincing growers to adopt preventative management, and our suggestions for how to resolve the challenge, may provide insights for preventative disease management to other study systems.

\section{ACKNOWLEDGMENTS}

We thank UCCE Advisors M. Cooper, R. Smith, M. Battany, G. McGourty, L. Wunderlich, and P. Verdegaal for organizing meetings at which the survey was conducted; and R. Travadon (University of California, Davis) for help with surveys. This research was funded by grant 2012-51181-19954 to K. Baumgartner, J. Kaplan, and M. Lubell from the United States Department of Agriculture National Institute of Food and Agriculture's Specialty Crops Research Initiative (SCRI) program.

\section{LITERATURE CITED}

Abadi Ghadim, A. K., and Pannell, D. J. 1999. A conceptual framework of adoption of an agricultural innovation. Agric. Econ. 21:145-154.

Bertsch, C., Ramirez Suero, M., Magnin Robert, M., Larignon, P., Chong, J., Abou Mansour, E., Spagnolo, A., Clement, C., and Fontaine, F. 2013. Grapevine trunk diseases: Complex and still poorly understood. Plant Pathol. 62:243-265.

Czemmel, S., Galarneau, E. R., Travadon, R., McElrone, A. J., Cramer, G. R., and Baumgartner, K. 2015. Genes expressed in grapevine leaves reveal latent wood infection by the fungal pathogen Neofusicoccum parvum. PLoS One 10:e0121828.

Duthie, J. A., Munkvold, G. P., Marois, J. J., Grant, S., and Chellemi, D. O. 1991. Relationship between age of vineyard and incidence of Eutypa dieback. (Abstr.) Phytopathology 81:1183.

Fullerton, A. S. 2009. A conceptual framework for ordered logistic regression models. Sociol. Methods Res. 38:306-347.

Gent, D. H., Mahaffee, W. F., McRoberts, N., and Pfender, W. F. 2013. The use and role of predictive systems in disease management. Annu. Rev. Phytopathol. 51:267-289.

Gu, S., Cochran, R. C., Du, G., Hakim, A., Fugelsang, K. C., Ledbetter, J., Ingles, C. A., and Verdegaal, P. S. 2005. Effect of training-pruning regimes on Eutypa dieback and performance of 'Cabernet Sauvignon' grapevines. J. Hortic. Sci. Biotechnol. 80:313-318.
Gubler, W. D., Rolshausen, P. E., and Trouillas, F. P. 2013. Eutypa dieback. Pages 110-116 in: Grape Pest Management, 3rd ed., L. J. Bettiga, ed. University of California, Division of Agriculture and Natural Resources, Oakland.

Hillis, V., Lubell, M., Kaplan, J., Doll, D., and Baumgartner, K. 2016. The role of pest-control advisers in preventative management of grapevine trunk diseases. Phytopathology 106:339-347.

Hoffman, M., Lubell, M., and Hillis, V. 2015. Network-smart extension could catalyze social learning. Calif. Agric. 69:113-122.

Jabbour, R., Zwickle, S., Gallandt, E. R., McPhee, K. E., Wilson, R. S., and Doohan, D. 2013. Mental models of organic weed management: Comparison of New England US farmer and expert models. Renew. Agric. Food Syst. 29:319-333.

Kaplan, J., Travadon, R., Cooper, M. L., Hillis, V., Lubell, M., and Baumgartner, K. 2016. Identifying economic hurdles to early adoption of preventative practices: The case of trunk diseases in California winegrape vineyards. Wine Econ. Policy 5:127-141.

Keller, M. 2015. The Science of Grapevines: Anatomy and Physiology, 2nd ed. Academic Press, London.

Lubell, M., Hillis, V., and Hoffman, M. 2011. Innovation, cooperation, and the perceived benefits and costs of sustainable agriculture practices. Ecol. Soc. 16:23.

McCullagh, P. 1980. Regression models for ordinal data. J. Royal Stat. Soc. 42:109-142.

McRoberts, N., Hall, C., Madden, L. V., and Hughes, G. 2011. Perceptions of disease risk: From social construction of subjective judgments to rational decision making. Phytopathology 101:654-665.

Merenlender, A. M. 2000. Mapping vineyard expansion provides information on agriculture and the environment. Calif. Agric. 54:7-12.

Munkvold, G. P., Duthie, A., and Marois, J. J. 1994. Reductions in yield and vegetative growth of grapevines due to Eutypa dieback. Phytopathology 84: 186-192.

Pannell, D. J., Marshall, G. R., Barr, N., Curtis, A., Vanclay, F., and Wilkinson, R. 2006. Understanding and promoting adoption of conservation practices by rural landholders. Aust. J. Exp. Agric. 46:1407-1424.

Petzoldt, C. H., Moller, W. J., and Sall, M. A. 1981. Eutypa dieback of grapevine: Seasonal differences in infection and duration of susceptibility of pruning wounds. Phytopathology 71:540-543.

R Core Team. 2013. A Language and Environment for Statistical Computing. R Foundation for Statistical Computing, Vienna. http://www.R-project.org/

Rogers, E. M. 2003. Diffusion of Innovations, 5th ed. Simon and Schuster, New York.

Rolshausen, P. E., Urbez-Torres, J. R., Rooney-Latham, S., Eskalen, A., Smith, R. J., and Gubler, W. D. 2010. Evaluation of pruning wound susceptibility and protection against fungi associated with grapevine trunk diseases. Am. J. Enol. Vitic. 61:113-119.

Siebert, J. B. 2001. Eutypa: The economic toll on vineyards. Wines Vines April:50-56.

Sipiora, M. J. and Cuellar, S. 2014. Economic impact of Eutypa dieback. Wine Bus. Mon. October:46-49.

Smyth, M., and Russell, J. 2009. 'From graft to bottle'-Analysis of energy use in viticulture and wine production and the potential for solar renewable technologies. Renew. Sustain. Energy Rev. 13:1985-1993.

Sosnowski, M. R., Wicks, T. J., and Scott, E. S. 2011. Control of Eutypa dieback in grapevines using remedial surgery. Phytopathol. Mediterr. 50: S277-S284.

Úrbez-Torres, J. R., Battany, M., Bettiga, L. J., Gispert, C., McGourty, G., Roncoroni, J., Smith, R. J., Verdegaal, P., and Gubler, W. D. 2010. Botryosphaeriaceae species spore-trapping studies in California vineyards. Plant Dis. 94:717-724.

Urbez-Torres, J. R., Leavitt, G. M., Guerrero, J. C., Guevara, J., Striegler, K., Allen, A., and Gubler, W. D. 2006. Identification of fungal pathogens associated with grapevine cankers in the main grapegrowing areas of the United States and Mexico. Phytopathol. Mediterr. 46:109-110.

Warner, K. E. 1974. The need for some innovative concepts of innovation: An examination of research on the diffusion of innovations. Policy Sci. 5: 433-451.

Weber, E. A., Trouillas, F. P., and Gubler, W. D. 2007. Double pruning of grapevines: A cultural practice to reduce infections by Eutypa lata. Am. J. Enol. Vitic. 58:61-66. 